\title{
Prostate stem cell antigen-targeted nanoparticles with dual functional properties: in vivo imaging and cancer chemotherapy
}

This article was published in the following Dove Press journal:

International Journal of Nanomedicine

27 July 2012

Number of times this article has been viewed

\author{
Xin Gao',* \\ Yun Luo',* \\ Yuanyuan Wangl,* \\ Jun Pang' \\ Chengde Liao $^{2}$ \\ Hanlun Lu ${ }^{3}$ \\ Youqiang Fang' \\ 'Department of Urology, The Third \\ Affiliated Hospital, ${ }^{2}$ Department \\ of Radiology, The Second Affiliated \\ Hospital, Sun Yat-Sen University, \\ ${ }^{3}$ Materials Science Institute of \\ Zhongshan University, Guangzhou, \\ China \\ *These authors contributed equally \\ to this work
}

Background: We designed dual-functional nanoparticles for in vivo application using a modified electrostatic and covalent layer-by-layer assembly strategy to address the challenge of assessment and treatment of hormone-refractory prostate cancer.

Methods: Core-shell nanoparticles were formulated by integrating three distinct functional components, ie, a core constituted by poly(D,L-lactic-co-glycolic acid), docetaxel, and hydrophobic superparamagnetic iron oxide nanocrystals (SPIONs), a multilayer shell formed by poly(allylamine hydrochloride) and two different sized poly(ethylene glycol) molecules, and a single-chain prostate stem cell antigen antibody conjugated to the nanoparticle surface for targeted delivery.

Results: Drug release profiles indicated that the dual-function nanoparticles had a sustained release pattern over 764 hours, and SPIONs could facilitate the controlled release of the drug in vitro. The nanoparticles showed increased antitumor efficiency and enhanced magnetic resonance imaging in vitro through targeted delivery of docetaxel and SPIONs to PC 3M cells. Moreover, in nude mice bearing PC3M xenografts, the nanoparticles provided MRI negative contrast enhancement, as well as halting and even reversing tumor growth during the 76-day study duration, and without significant systemic toxicity. The lifespan of the mice treated with these targeted dual-function nanoparticles was significantly increased (Chi-square $=22.514$, $P<0.0001)$.

Conclusion: This dual-function nanomedical platform may be a promising candidate for tumor imaging and targeted delivery of chemotherapeutic agents in vivo.

Keywords: nanoparticle, prostate cancer, targeting, chemotherapy, imaging

\section{Introduction}

Although substantial improvement has been made in the diagnosis and treatment of prostate cancer, the prognosis remains poor for patients who suffer from hormonerefractory prostate cancer. ${ }^{1}$ Currently, the treatment of hormone-refractory prostate cancer relies mainly on docetaxel-based chemotherapy. However, the application of docetaxel is compromised by its hydrophobic nature, nonselective toxicity, and propensity to induce multidrug resistance. ${ }^{2}$ Moreover, it is difficult to determine the effects of cancer therapy owing to the lack of specific and sensitive assessment modalities in clinical practice. ${ }^{3}$ Promisingly, multifunctional nanomedical platforms, by incorporating different capabilities and targeting strategies, are demonstrating potential sophistication, ${ }^{4,5}$ and greatly improving cancer diagnosis and therapeutic efficacy. ${ }^{4,6,7}$ However, an ongoing challenge is that multifunctional nanoparticles for in vivo application are required to be stable in the circulation, to be stealthy to evade 
clearance by the reticuloendothelial system, and to have reactive groups on their surface for efficient conjugation of specific targeting ligands. ${ }^{8}$ Furthermore, penetration of the nanoparticles into cancer tissue that is distal from the blood vessels in vivo is influenced by the affinity and specificity of targeting ligands. ${ }^{9}$ Labeled with the appropriate antibodies to tumor membrane antigens, nanoparticles offer great specificity and sensitivity. ${ }^{10}$ One potential candidate, overexpressed in both local and metastatic prostate cancer, is prostate stem cell antigen. ${ }^{11,12}$ In contrast with other prostate cancer-associated tumor antigens, prostate stem cell antigen has been recognized as a truly prostate-specific membranebound protein, which participates in membrane recycling and becomes internalized by ligand-induced endocytosis. ${ }^{11}$ In this study, we engineered a dual-function nanoparticlebased system for in vivo application using an electrostatic and covalent layer-by-layer assembly strategy. ${ }^{13}$ Our formulations were characterized by a core-shell structure with a hydrophobic core providing a natural carrier environment for hydrophobic imaging and chemotherapeutic agents, and a multilayer shell endowing the particle with high aqueous dispersity, antibiofouling properties, and stability in vivo. ${ }^{14}$ In addition, poly(D,L-lactic-co-glycolic acid) (PLGA) has been approved by the US Food and Drug Administration for clinical use, ${ }^{14}$ and superparamagnetic iron oxide nanocrystals (SPIONs) could be degraded to become incorporated into the hemoglobin pool in vivo, ${ }^{15}$ which may facilitate the translation of our vehicles into clinical practice. A surface-localized $\mathrm{scAb}$ antibody provided targeted delivery to prostate stem cell antigen-positive cancer cells with high selectivity and binding affinity, but had a smaller size than an intact antibody. ${ }^{16}$ The efficacy of dual-function nanoparticles and their targeting capability were assessed in vitro and in vivo.

\section{Materials and methods Materials}

Carboxyl-modified poly(D,L-lactic-co-glycolic acid) (PLGA-COOH, 50:50, Resomer ${ }^{\circledR}, 34 \mathrm{kDa}$ ) was purchased from Absorbable Polymers International (Pelham, AL). Heterofunctional poly(ethylene glycol) (PEG) terminated by carboxylic acid and maleimide (mal-PEG-COOH, $3.4 \mathrm{kDa}$ ) and carboxyl terminal groups of methoxy(polyethylene glycol) (mPEG-COOH, $2 \mathrm{kDa}$ ) were obtained from Peking Jenkem Technology Co, Ltd (Beijing, China). Docetaxel, poly(allylamine hydrochloride) (PAH), and the other chemicals were purchased from Sigma-Aldrich (St Louis, MO). The mouse monoclonal antibody against prostate stem cell antigen and phycoerythrin (PE)-labeled goat antimouse
IgG were obtained from Santa Cruz Biotechnology Inc (Santa Cruz, CA). PC3M and HT29 cells were ordered from the American Type Culture Collection (Manassas, VA). Cell culture medium and fetal bovine serum were purchased from Invitrogen Corporation (Carlsbad, CA). Hydrophobic SPIONs $(6 \mathrm{~nm})$ were synthesized using a previously described method. ${ }^{17,18}$

\section{Preparation of scAb-PLGA-SPIO/ docetaxel nanoparticles $\mathrm{COOH}-\mathrm{PLGA}-\mathrm{SPIO} /$ docetaxel nanoparticles}

SPIO/docetaxel-PLGA-COOH nanoparticles were prepared using a single emulsion evaporation method with some modification. Briefly, hydrophobic SPIO $(2 \mathrm{mg} / \mathrm{mL})$ and docetaxel $(2 \mathrm{mg} / \mathrm{mL})$ were dispersed in $2 \mathrm{~mL}$ of dichloromethane followed by addition of $20 \mathrm{mg}$ of PLGA-COOH. The mixture was homogenized for 20 minutes to obtain a dispersion of SPIO, PLGA, and docetaxel. The organic phase obtained was added to $10 \mathrm{~mL}$ of an aqueous solution containing $2 \%$ $(\mathrm{w} / \mathrm{v})$ polyvinyl alcohol and emulsified with a homogenizer for 5 minutes, and followed by 2 minutes of ultrasonication using a probe type sonicator over an ice bath. The emulsion was slowly dropped into $90 \mathrm{~mL}$ of $0.3 \%(\mathrm{w} / \mathrm{v})$ polyvinyl alcohol solution and allowed to stir overnight in the fume hood to evaporate the organic solvent. The suspension was centrifuged at $1000 \mathrm{rpm}$ to remove any larger aggregates. The nanoparticles were collected by centrifugal ultrafiltration, washed with deionized water, and resuspended for use.

\section{$\mathrm{H}_{2} \mathrm{~N}$-PLGA-SPIO/docetaxel nanoparticles}

Amino-modified PLGA nanoparticles were prepared according to a previously reported method. ${ }^{19,20}$ In brief, $5 \mathrm{mg}$ of COOH-PLGA-SPIO/docetaxel nanoparticles was dispersed in $20 \mathrm{~mL}$ of water and ultrasonicated for 5 minutes in an ice bath. Then, $20 \mu \mathrm{L}$ of $\mathrm{NH}_{3} \cdot \mathrm{H}_{2} \mathrm{O}(28-30 \mathrm{wt} \%)$ was added into the suspension to produce a weakly basic solution, $20 \mu \mathrm{L}$ of aqueous PAH (10 mg/mL) was introduced, and the mixture suspension was ultrasonicated for 20 minutes in an ice bath. The PAH-modified PLGA nanoparticles were collected by magnetic field-guided accumulation, washed with water, and dispersed for subsequent experiments.

\section{Synthesis of scAb-PEG ${ }_{3400}-\mathrm{COOH}$}

$\mathrm{scAb}$-bearing free sulfhydryl groups were prepared before conjugation with mal-PEG-COOH, as described by Chen et al. ${ }^{21}$ Next, $100 \mu \mathrm{L}$ of ethylenediaminetetraacetic acid (EDTA) aqueous solution $(0.5 \mathrm{M})$ was added into $500 \mu \mathrm{L}$ of prostate stem cell antigen antibody in aqueous solution $(0.2 \mu \mathrm{g} / \mu \mathrm{L})$ 
and incubated for 15 minutes at $4^{\circ} \mathrm{C}$. 2-Mercaptoethylamine (300 mg) was dissolved in a mixture of $2.94 \mathrm{~mL}$ of phosphatebuffered solution and $60 \mu \mathrm{L}$ of $0.5 \mathrm{M}$ EDTA aqueous solution, and then mixed with the prostate stem cell antigen antibody solution. After incubation for 90 minutes at $37^{\circ} \mathrm{C}$, the scAb solution obtained was purified three times with phosphatebuffered solution ( $\mathrm{pH} 7.4$, each $1 \mathrm{~mL}$ containing $20 \mu \mathrm{L}$ of 0.5 M EDTA solution) by ultrafiltration (Amicon Ultra-4 centrifugal filter, regenerated cellulose membrane, molecular weight cutoff $10 \mathrm{kDa}$ ). Next, $100 \mu \mathrm{g}$ of mal-PEG ${ }_{3400}-\mathrm{COOH}$ aqueous solution (dissolved in a mixture of $98 \mu \mathrm{L}$ phosphate-buffered solution and $2 \mu \mathrm{L}$ of $0.5 \mathrm{M}$ EDTA solution) was mixed with the purified scAb solution and incubated overnight at $4^{\circ} \mathrm{C}$. The scAb-functionalized PEG (scAb-PEG-COOH) was washed three times with phosphate-buffered solution ( $\mathrm{pH}$ 7.4) using a Sepharose CL-4B column (GE Healthcare UK Limited, Buckinghamshire, UK) to remove the free mal-PEG-COOH.

\section{scAb-PLGA-SPIO-docetaxel nanoparticles}

$\mathrm{scAb}-\mathrm{PEG}_{3400}-\mathrm{COOH} 84.7 \mu \mathrm{g}$ was mixed with $\mathrm{mPEG}_{2000}-\mathrm{COOH} 81.8 \mu \mathrm{g}$ in phosphate-buffered solution ( $\mathrm{pH}$ 6.3) followed by addition of 1-ethyl-3-(3dimethylaminopropyl)-carbodiimide) (EDC) $500 \mu \mathrm{g}$ and $\mathrm{N}$-hydroxysuccinimide (NHS) $500 \mu \mathrm{g}$. After incubation for 20 minutes at room temperature, $1.72 \mathrm{mg}$ of PAH-modified nanoparticles $\left(\mathrm{H}_{2} \mathrm{~N}-\mathrm{PLGA}-\mathrm{SPIO} /\right.$ docetaxel) were added and incubated overnight at $4^{\circ} \mathrm{C}$ after homogenization. The scAbPLGA-SPIO/docetaxel nanoparticles were purified using a centrifugal filter with a $100 \mathrm{kDa}$ molecular weight cutoff (Millipore, MA). scAb-PLGA/docetaxel, PLGA/docetaxel, and scAb-PLGA-SPIO were prepared in a similar manner and used as a control. For imaging, PLGA- SPIO/ coumarin and scAb-PLGA-SPIO/coumarin were synthesized using coumarin instead of docetaxel.

\section{Determination of $s c A b$ on nanoparticle surface}

The $\mathrm{scAb}$ on the nanoparticle surface was confirmed using flow cytometry, confocal laser scanning microscopy (CLSM) and protein assay. For flow cytometry, a dispersion of PLGA-SPIO/docetaxel or scAb-PLGA-SPIO/docetaxel was incubated with goat antimouse IgG-PE diluted in phosphate-buffered solution containing $0.9 \%$ bovine serum albumin for one hour at room temperature. The nanoparticles were purified by centrifugation, washed three times, resuspended, and introduced into a flow cytometer. The fluorescence intensity was analyzed using a FAC Scan flow cytometer (Becton Dickinson, Franklin Lakes, NJ) as described previously. ${ }^{22}$ scAb-PLGA-SPIO/docetaxel was directly analyzed as a blank control. For confocal microscopy, the scAb-PLGA-SPIO/coumarin was incubated with goat antimouse lgG-PE diluted with phosphate-buffered solution containing $0.9 \%$ bovine serum albumin for one hour, collected by centrifugation, washed, and resuspended before being imaged under a confocal microscope (LSM 510 Meta, Carl Zeiss, Jena, Germany). The amount of protein in the scAb-PLGA-SPIO/Dtxl was quantified using a bicinchoninic acid protein assay, as previously described. 22,23

\section{Nanoparticle characterization}

\section{Particle size and transmission electron microscopy}

The particle size distribution and zeta potential were determined using a ZetaPALS dynamic light-scattering detector (15 mW laser, incident beam $676 \mathrm{~nm}$, Brookhaven Instruments, Holtsville, NY). The morphology of the nanoparticles was characterized using TEM with a JEOL JEM-200CX instrument at an acceleration voltage of $200 \mathrm{kV}$. A dispersion of nanoparticles was dropped onto a carbon-coated copper grid, dried in air at room temperature, and imaged within 24 hours.

\section{Determination of SPIO and docetaxel content}

The SPIO loading was quantified using a polarized Zeeman atomic absorption spectrophotometer (Model Z-2000 series). In brief, preweighed lyophilized nanoparticles were dispersed in $1 \mathrm{M}$ aqueous solution of $\mathrm{HCl}$ to dissolve the SPIONs completely. The iron concentration was then determined by measuring the specific Fe absorption at around $248.3 \mathrm{~nm}$ and calibrated with Fe standard solutions. The SPIO-loading content was calculated as the ratio of iron oxide to the total weight of the nanoparticle sample. To determine the docetaxel content, $2 \mathrm{~mL}$ of acetonitrile was added to the same lyophilized sample for drug extraction. The sample was kept on a shaker rotating at $100 \mathrm{rpm}$ for 48 hours at room temperature before addition of $4 \mathrm{~mL}$ of methanol. After centrifugation, the docetaxel content in the supernatant was measured by high-pressure liquid chromatography (Agilent 1100, Palo Alto, CA) equipped with a pentafluorophenyl column (Curosil-PFP, $250 \times 4.6 \mathrm{~mm}, 5 \mu \mathrm{m}$, Phenomenex, Torrance, CA). Absorbance at $227 \mathrm{~nm}$ was measured to determine the docetaxel content using a previously established calibration. The dialysis method was used to monitor the release of docetaxel, as described previously. ${ }^{2}$

\section{Phantom MRI}

Dual-function nanoparticles $(800 \mu \mathrm{L}$ in phosphate-buffered solution) were dispersed in $200 \mu \mathrm{L}$ of $2 \%$ (w/v) agar phosphate-buffered solution at a final concentration of 
0-40 $\mu \mathrm{g} / \mathrm{mL}$ Fe while warm and allowed to cool to room temperature. The prepared gels were positioned in a $1.5 \mathrm{~T} \mathrm{MR}$ scanner (GE Healthcare UK Limited) at room temperature. To estimate the transverse relaxation time $\left(\mathrm{T}_{2}\right)$, the images were acquired at different echo times with a repetition time of $5000 \mathrm{msec}$ (spin echo $\mathrm{T}_{2}$-weighted imaging, field of view $150 \mathrm{~mm} \times 150 \mathrm{~mm}$, matrix $256 \times 256$, slice thickness $1.5 \mathrm{~mm}$ ). The magnitude of the image intensities was measured within manually drawn regions of interest (ROI). $\mathrm{T}_{2}$ was obtained by fitting the data to a monoexponential decay curve using linearized least-squares optimization. $\mathrm{T}_{2}$ relaxivity $\left(\mathrm{r}_{2}, \mathrm{~s}^{-} \mu \mathrm{g}^{-} \mathrm{mL}\right)$ was calculated as the slope of relaxation rate $\left(s^{-}, 1 / T 2\right)$ versus Fe concentration relationship.

\section{In vitro cytotoxicity assay}

Cytotoxicity was analyzed using the Cell Counting Kit- 8 (CCK-8) assay according to the manufacturer's protocol (Dojindo, Kumamoto, Japan). PC3M cells were seeded in 96-well plates at $2.5 \times 10^{3} /$ well and allowed to undergo attachment. The cells were treated with docetaxel, PLGA/ docetaxel, scAb-PLGA/docetaxel, PLGA-SPIO/docetaxel, scAb-PLGA-SPIO/docetaxel, and scAb-PLGA-SPIO at different concentrations for 24, 48, and 72 hours. Following treatment, the medium was replaced and no further dose of drug was added. After a further 4 days of incubation, $10 \mu \mathrm{L}$ of CCK-8 solution was added. After incubation for $1-4$ hours at $37^{\circ} \mathrm{C}$, absorbance at $450 \mathrm{~nm}$ was measured using a microplate reader. $\mathrm{IC}_{50}$ values were quantitatively calculated by GraphPad Prism GraphPad Software (San Diego, CA) using nonlinear regression analysis.

\section{Cellular uptake}

Cellular uptake experiments were conducted as previously reported. ${ }^{24}$ In brief, PC3M cells were seeded in 6-well plates at $5 \times 10^{5}$ cells per well and allowed to attach for 24 hours. The medium was replaced with $2 \mathrm{~mL}$ of freshly prepared nanoparticle-containing medium $(50 \mathrm{ng} / \mathrm{mL}$ docetaxel) and incubated for 2 hours. To examine the specificity of scAbmediated uptake, PC3M cells were incubated with excess free prostate stem cell antigen monoclonal antibodies before incubation with scAb-PLGA-SPIO/docetaxel. The cells were washed six times, collected, and lysed in $100 \mu \mathrm{L}$ of cell lysis buffer for 10 minutes. An aliquot was used for cell protein determination (bicinchoninic acid protein assay kit, Pierce, Rockford, IL). The docetaxel in the remaining portion was extracted by acetonitrile/methanol and then quantified by high-pressure liquid chromatography after centrifugation at $14,000 \mathrm{rpm}$ for 10 minutes using a previously established calibration. The data were normalized to per milligram cell protein.

\section{In vitro $M R I$ scan}

PC3M cells and HT29 cells were seeded into $60 \mathrm{~mm}$ plates at a density of $1 \times 10^{6}$ cells. After reaching $80 \%$ confluence, PC3M cells were incubated with PLGA-SPIO/docetaxel or scAb-PLGA-SPIO/docetaxel, and HT29 cells were incubated with scAb-PLGA-SPIO/docetaxel at an equivalent Fe concentration $(15 \mu \mathrm{g} / \mathrm{mL} \mathrm{Fe})$. After incubation for one hour, the cells were washed, trypsinized, and collected by centrifugation. The cells were then fixed in 1\% paraformaldehyde for one hour at $4^{\circ} \mathrm{C}$ and dispersed in $300 \mu \mathrm{L} 0.4 \%$ (w/v) phosphate-buffered agar. The cells were scanned under a 1.5 T MR scanner, and the $\mathrm{T}_{2}$ value was determined as described in the MRI phantom. Untreated PC3M cells were used as a blank control.

\section{Flow cytometry assay}

PLGA-SPIO/coumarin and scAb-PLGA-SPIO/coumarin were used to perform the flow cytometry assay because of the fluorescence of coumarin. $1 \times 10^{6}$ cells of PC3M or HT29 were incubated with PLGA-SPIO/coumarin, scAb-PLGA$\mathrm{SPIO}$ /coumarin, or void nanoparticles in culture medium at an equivalent concentration of coumarin $(5 \mu \mathrm{g} / \mathrm{mL})$ for 30 minutes at $37^{\circ} \mathrm{C}$. The cells were then pelleted by centrifugation. Thereafter, the cells were washed immediately and analyzed using a flow cytometer (Becton Dickinson).

\section{Confocal laser scanning microscopy}

PC3M and HT29 cells were seeded in Bioptechs plates at 50,000 cells/plate and incubated overnight. The cells were rinsed twice with phosphate-buffered solution ( $\mathrm{pH}$ 7.2) and preincubated at $37^{\circ} \mathrm{C}$ for one hour in serum-free medium. PLGA-SPIO/coumarin, scAb-PLGA-SPIO/coumarin, or void nanoparticles were added at an equivalent concentration of coumarin $(5 \mu \mathrm{g} / \mathrm{mL})$ and incubated for 2 hours at $37^{\circ} \mathrm{C}$. The free nanoparticles were aspirated, and the cells were washed three times with phosphate-buffered solution and fixed with $4 \%$ paraformaldehyde solution for 20 minutes. Afterwards, the cells were counterstained for another 20 minutes with DAPI ( $1 \mathrm{mg} / \mathrm{mL})$. The cells were imaged under a confocal microscope (LSM 510 Meta, Carl Zeiss, Gottingen, Germany). Fluorescence intensity was analyzed by Image J 1.43.

\section{Xenograft preparation}

All animal studies were conducted in accordance with the guidelines of the Institutional Animal Care and Use Committee at the University of Sun Yat-sen University. 
Male BALB/c nude mice aged 6-8 weeks were purchased from Vital River Laboratories (Peking, China). To establish a xenograft, $3 \times 10^{6}$ PC3M cells were suspended in $100 \mu \mathrm{L}$ of phosphate-buffered solution and injected subcutaneously into the upper right flank.

\section{In vivo $M R I$}

scAb-PLGA-SPIO/docetaxel or PLGA-SPIO/docetaxel was injected through the tail vein at designated time points $(5 \mathrm{mg}$ $\mathrm{Fe} / \mathrm{kg}$ per mouse). Afterwards, tumor-bearing mice were anesthetized with 1\%-2.5\% isoflurane (Abbott Laboratories, Abbott Park, IL) and placed in a $1.5 \mathrm{~T}$ MR scanner. T2-weighted images were acquired on a small animal MRI system using the following imaging parameters: spin-echo T2-weighted imaging, repetition time $1600 \mathrm{msec}$, echo time $80 \mathrm{msec}$, field of view $40 \times 40$, thickness $1 \mathrm{~mm}$, NEX 1.0, and echo $1 / 1$. The MRI signal intensity of tumor regions and leg muscles was measured within a defined ROI. Untreated tumor-bearing mice were used as a control.

\section{In vivo antitumor efficacy}

Tumor xenografts were allowed to reach approximately $300 \mathrm{~mm}^{3}$ before the mice received different treatments. Based on the previously reported maximal tolerated dose, ${ }^{14}$ tumor-bearing mice were treated by tail vein injection of phosphate-buffered solution, docetaxel (dissolved in dimethyl sulfoxide), scAb-PLGA-SPIO, PLGA-SPIO/ docetaxel, or scAb-PLGA-SPIO/docetaxel five times every three days (total dose of $50 \mathrm{mg}$ docetaxel $/ \mathrm{kg}$ ). Body weight and tumor size were also monitored every three days. The dimensions of the tumor were estimated in two perpendicular directions (length and width) using a caliper and the volumes were calculated by $0.5 \times$ length $\times$ width $^{2}$. When the body weight loss persisted beyond $20 \%$ of the predosing weight or tumor volume exceeded $800 \mathrm{~mm}^{3}$, the mice were deemed to have reached the endpoint and were euthanized. At the endpoint, blood samples were collected from the orbital sinus, and white blood cell counts were then determined.

\section{Hematoxylin-eosin staining and immunohistochemical detection of apoptosis}

After each mouse was sacrificed, tumor tissues were immediately removed, fixed in 10\% formalin, paraffin-embedded, and stained with hematoxylin-eosin using a standard clinical laboratory protocol. Terminal transferase uridyl nick-end labeling (TUNEL) staining was performed using a DeadEnd ${ }^{\mathrm{TM}}$ Colorimetric TUNEL system according to the manufacturer's instructions (Promega, Madison, WI). In brief, after deparaffinization and antigen retrieval, the sections were incorporated with biotinylated nucleotide at the $3^{\prime}-\mathrm{OH}$ DNA ends using the recombinant terminal deoxynucleotidyl transferase (rTdT) enzyme and incubated for one hour at $37^{\circ} \mathrm{C}$. Horseradish peroxidase-labeled streptavidin was bound to biotinylated nucleotides, and was detected using diaminobenzidine. Images were captured with an Olympus AX70 microscope (Olympus, Stockholm, Sweden).

\section{Statistical analysis}

The data were expressed as the mean \pm standard deviation. Statistical significance was determined using the Student's $t$-test or analysis of variance with Tukey's test. $P<0.05$ was considered to be statistically significant.

\section{Results and discussion Dual-function nanoparticle formulation}

a schematic diagram of the nanoparticle formulation (scAb-PLGA-SPIO/docetaxel) is shown in Figure 1. The spherical, highly ordered SPIONs were hydrophobic owing to an oleic acid/oleylamine coating, which was essential for encapsulation. After SPIO and docetaxel were encapsulated into PLGA-COOH through an oil-in-water $(\mathrm{o} / \mathrm{w})$ emulsion and subsequent solvent evaporation, ${ }^{25}$ the nanoparticle surface was negatively charged as a result of the carboxy groups on the terminal of PLGA. The nanoparticles were then coated with a layer of positively charged PAH through electrostatic interaction, ${ }^{26}$ grafting active amino groups on the surface. Prostate stem cell antigen antibodies were pretreated with 2-mercaptoethylamine to yield scAb-bearing free sulfhydryl groups. To protect the biological activity of scAb, we initially conjugated $\mathrm{scAb}$ with the unstable maleimide group of mal- $\mathrm{PEG}_{3400}-\mathrm{COOH}$ in aqueous solution through a covalent thiol-maleimide linkage. Subsequently, the resulting scAb$\mathrm{PEG}_{3400}-\mathrm{COOH}$ was mixed with $\mathrm{mPEG}_{2000}-\mathrm{COOH}$, and then attached to PAH-modified PLGA nanoparticles using EDC/ NHS as catalysts to impart active targeting and "stealthiness" characteristics to the nanoparticle. Thus, we successfully avoided the coupling reaction between the maleimide group and the amino group on the surfaces of the PAH-modified PLGA nanoparticles. ${ }^{27}$ Herein, $\mathrm{mPEG}_{2000}$, as the major component, formed a "corona" around the core, and mal-PEG ${ }_{3400}$, as the functionalized component was conjugated with the targeting moiety. Most important, scAb-functionalized $\mathrm{PEG}_{3400}$ protruded from the $\mathrm{PEG}_{2000}$ corona for active tumor targeting due to its higher molecular weight. The density 


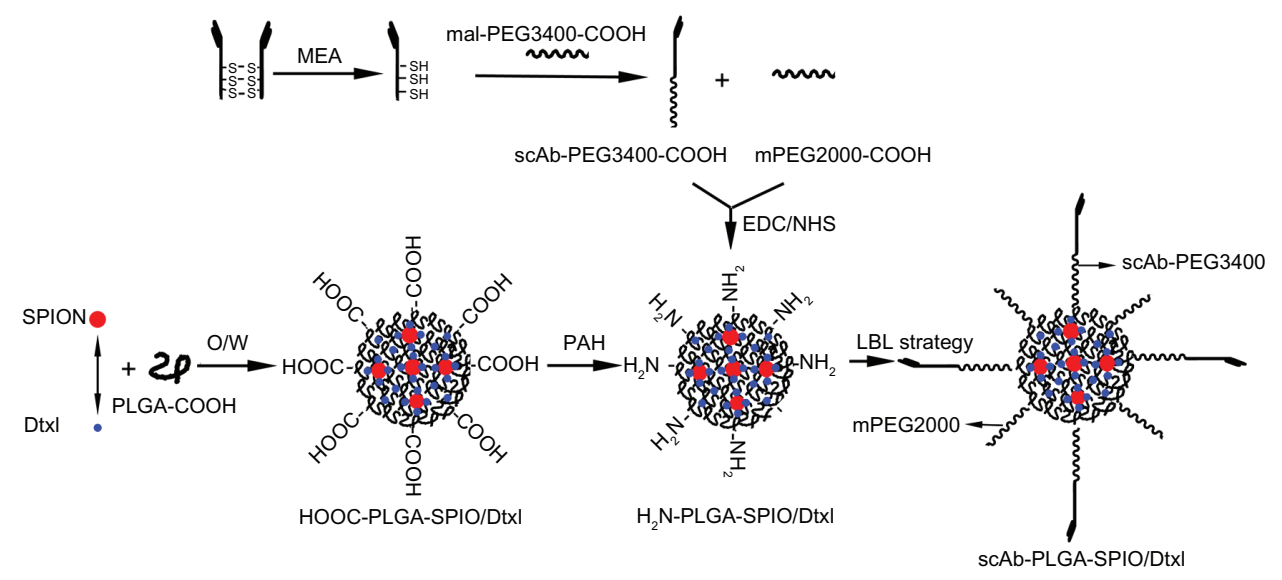

Figure I Synthetic scheme and preparation process for scAb-PLGA-SPIO/docetaxel using layer-by-layer strategy.

Abbreviations: PEG, poly(ethylene glycol); EDC, I-ethyl-3-(3-dimethylaminopropyl)-carbodiimide; NHS, N-hydroxysuccinimide; PAH, poly(allylamine hydrochloride); PLGA, poly(D,L-lactic-co-glycolic acid); SPION, superparamagnetic iron oxide nanoparticles; Dtxl, docetaxel.

of $\mathrm{scAb}$ on the nanoparticle surface could be optimized by varying the ratio of scAb-PEG $\mathrm{PE}_{3400}$ to $\mathrm{mPEG}_{2000}$. The targeting capability could be maximized by avoiding the unnecessary masking of scAb on the nanoparticle surface, which may compromise passive targeting. ${ }^{28}$ The nanoparticles synthesized were stable under physiological conditions, without noticeable aggregation (Figure S1).

\section{Determination of scAb on nanoparticle surface}

To determine the presence of scAb on the nanoparticle surface, we used PE-labeled secondary antibodies to recognize scAb. To avoid nonspecific recognition and absorption, we incubated the nanoparticles with secondary antibody solution containing $0.9 \%$ bovine serum albumin. As shown in Figure 2C, the blank control showed no red fluorescence, as determined by flow cytometry. In comparison with PLGASPIO/docetaxel (scAb-free nanoparticles), a substantial shift of PE fluorescence was demonstrated in scAb-PLGASPIO/docetaxel (scAb-conjugated nanoparticles), confirming the presence of $\mathrm{scAb}$ on the nanoparticle surface. Minor red fluorescence was also observed for PLGA-SPIO/docetaxel, which may be attributed to nonspecific adsorption of the secondary antibodies. Further, the results suggest that the targeted nanoparticles were almost conjugated with $\mathrm{scAb}$. In order to visualize $\mathrm{scAb}$ on the nanoparticle surface by confocal laser scanning microscopy directly, coumarin was encapsulated into the nanoparticles instead of docetaxel as a probe. Unlike PLGA-SPIO/docetaxel (Figure 2B), scAb-PLGA-SPIO/docetaxel showed merged $\mathrm{red} /$ green fluorescence (Figure 2A), indicating that $\mathrm{scAb}$ was successfully conjugated with the nanoparticles, which agreed well with the results obtained by flow cytometry. It should be pointed out that the capacity of scAb to bind with secondary antibodies indicates that thiolation of antibodies may not affect their bioactivity. ${ }^{29} \mathrm{scAb}$ conjugated with nanoparticles was quantified using the bicinchoninic acid protein assay, and was approximately $28.3 \pm 6.7 \mu \mathrm{g}$ per $\mathrm{mg}$ of scAb-PLGA-SPIO/docetaxel.

\section{Biophysicochemical characteristics and in vitro release behavior}

Dynamic light scattering provided information on the hydrodynamic particle size of whole clusters, and showed

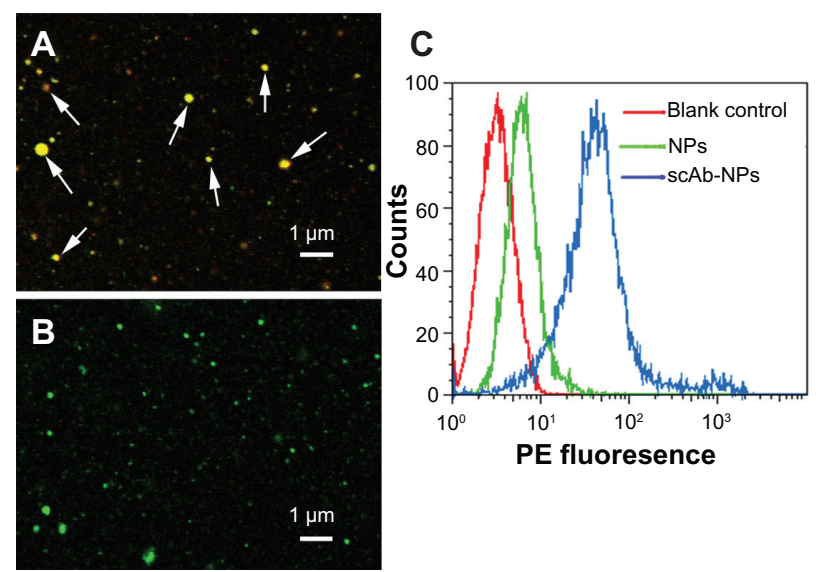

Figure 2 Determination of scAb on the nanoparticle surface. Confocal microscopic images of coumarin(green)-loaded scAb-PLGA-SPIO/coumarin (A) and PLGA-SPIO/ coumarin (B) incubated with $\mathrm{PE}(\mathrm{red})$-labeled secondary antibodies. The merged fluorescence indicated by the arrows demonstrates that scAb was successfully conjugated to the nanoparticle surface. (C) A significant shift of PE fluorescence intensity could be observed for scAb-PLGA-SPIO/docetaxel (scAb-NPs) in comparison with blank control and PLGA-SPIO/docetaxel NPs, indicating the presence of scAb on the nanoparticle surface.

Abbreviations: NPs, nanoparticles; PLGA, poly(D,L-lactic-co-glycolic acid); SPIO, superparamagnetic iron oxide; PE, phycoerythrin. 
that the diameter of scAb-PLGA-SPIO/docetaxel was $187.4 \pm 32.7 \mathrm{~nm}$ in phosphate-buffered solution (Figure $3 \mathrm{~A}$ ). The morphology of scAb-PLGA-SPIO/docetaxel was examined by TEM (Figure 3B). TEM observation provided evidence of successful encapsulation of clustered SPION into the PLGA core, which could result in increased $\mathrm{T}_{2}$ relaxivity compared with individual SPION. ${ }^{18}$ Docetaxel and SPION were simultaneously encapsulated into scAb-PLGA-SPIO/ docetaxel at $4.9 \% \pm 1.69 \% \mathrm{w} / \mathrm{w}$ and $5.41 \% \pm 1.23 \% \mathrm{w} / \mathrm{w}$, respectively. The in vitro drug release profiles are shown in Figure 3E. An initial burst of $24.2 \%$ and $41.1 \%$ accumulative release was observed in the first 48 hours for scAb-PLGA$\mathrm{SPIO} /$ docetaxel and scAb-PLGA/docetaxel, respectively, followed by sustained release. Cumulative release over the 764-hour period was $75.9 \%$ and $83 \%$ for scAb-PLGA-SPIO/ docetaxel and scAb-PLGA/docetaxel, respectively. The initial release could be because of diffusion of docetaxel from the hydrophobic core due to the difference in concentration gradient with the outside environment, whereas the slow, diffusion-controlled process possibly depended on the rate of polymer biodegradation. ${ }^{30}$ scAb-PLGA-SPIO/docetaxel demonstrated a significantly slower drug release profile than did scAb-PLGA/docetaxel, indicating that introduction of hydrophobic SPION into the system may facilitate controlled release of the drug. This may be understandable because docetaxel can partition into the oleic acid/oleylamine coating of SPION to promote drug retention further in the core. ${ }^{6,31}$

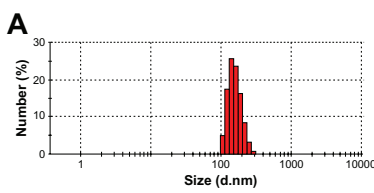

B
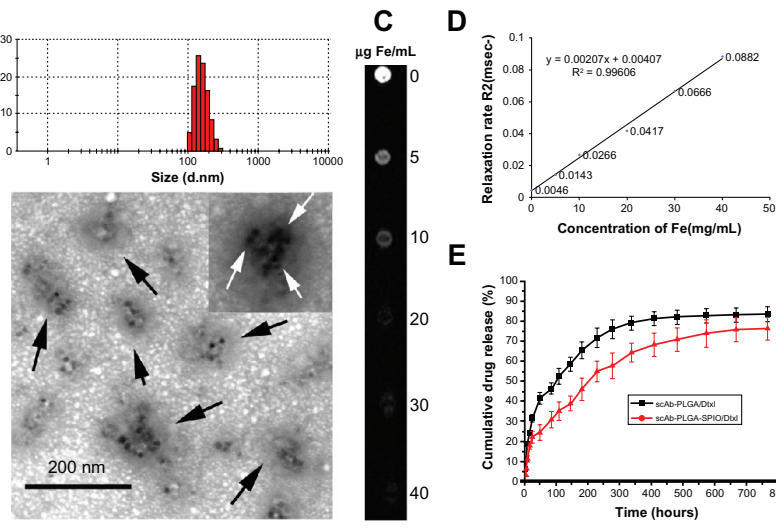

E

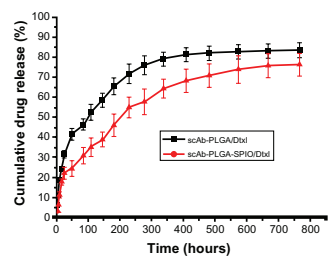

Figure 3 (A) Dynamic light scattering histogram showing the size distribution of scAb-PLGA-SPIO/docetaxel. (B) Transmission electron microscopic images of scAb-PLGA-SPIO/docetaxel. The nanoparticles were indicated by black arrows, and SPIO nanoparticles are shown with white arrows. (C) $\mathrm{T}_{2}$-weighted magnetic resonance images (repetition time $5000 \mathrm{msec}$, echo time $100 \mathrm{msec}$ ) of scAb-PLGA$\mathrm{SPIO} /$ docetaxel at various iron concentrations. (D) $\mathrm{T}_{2}$ relaxation rate as a function of the iron concentration of scAb-PLGA-SPIO/docetaxel. (E) In vitro docetaxel release profiles indicate that scAb-PLGA-SPIO/docetaxel showed slower drug release than scAb-PLGA/docetaxel.

Note: Results are shown as the mean \pm standard error of the mean $(n=3)$.

Abbreviations: Dtxl, docetaxel; PLGA, poly(D,L-lactic-co-glycolic acid); SPIO, superparamagnetic iron oxide.
This sustained release pattern that allows for the presence of docetaxel within the tumor over an extended period is a prerequisite for preventing drug resistance and improving therapeutic efficacy. ${ }^{32}$ The release of SPION was not detectable within 764 hours.

\section{MRI phantom}

The effect of scAb-PLGA-SPIO/docetaxel on $\mathrm{T}_{2}$ shortening was caused by the large susceptibility difference between the magnetic nanocrystals and surrounding medium, resulting in microscopic magnetic field inhomogeneity in the presence of an externally applied magnetic field. $T_{2}$ relaxivity $\left(r_{2}\right)$ was generally used to evaluate the sensitivity of contrastenhancing properties, and was determined from the slope of the linear fit of $1 / \mathrm{T}_{2}$ versus Fe concentration. Our results demonstrate that the magnetism of scAb-PLGA-SPIO/ docetaxel was readily detectable by MRI (Figure 3C), and the MRI signal intensity decreased with the increase in scAb-PLGA-SPIO/docetaxel concentration. As expected, the relaxation rate $R_{2}\left(R_{2}=1 / T_{2}\right)$ was linearly proportional to the Fe concentration within the analyzed concentration range (Figure 3D), and the $r_{2}$ of scAb-PLGA-SPIO/docetaxel was measured to be $2.07 \mathrm{~s}^{-} \mu \mathrm{g}^{-} \mathrm{mL}$.

\section{In vitro cytotoxicity and intracellular docetaxel concentration}

In vitro antitumor activity is shown in Figure 4A. Both docetaxel and the nanoparticles showed a sigmoidal dosedependent cytotoxic effect on PC3M cells, as previously described. ${ }^{2}$ Longer incubation or increased concentration led to an overall decrease in cell viability. The scAb-conjugated nanoparticles showed a significantly antiproliferative advantage over scAb-free nanoparticles. The $\mathrm{IC}_{50}$ values of scAb-PLGA-SPIO/docetaxel were 1.38-fold, 1.68-fold, and 1.95-fold lower than those for PLGA-SPIO/docetaxel at 24, 48 , and 72 hours, respectively. In contrast, the $\mathrm{IC}_{50}$ of scAbPLGA-SPIO/docetaxel showed no significant difference compared with that of PLGA-SPIO/docetaxel in HT29 cells (Figure S2). Relative to the free drug, scAb-PLGA-SPIO/ docetaxel showed approximately the same cytotoxic effect as docetaxel at 24 hours, but higher antitumor potential at 48 and 72 hours. A possible explanation can be proposed for the enhanced efficacy of nanoparticles relative to free drug even though only a portion of drug loaded in nanoparticles was released during the period that the drug-loaded polymeric nanoparticles were believed to circumvent the multidrug resistance effect derived from expression of the P-glycoprotein pump. ${ }^{33}$ Wang et al demonstrated that the 
A

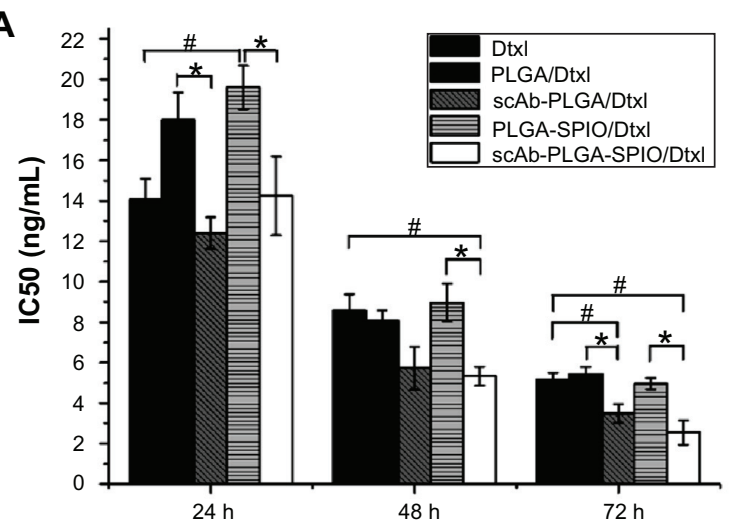

C

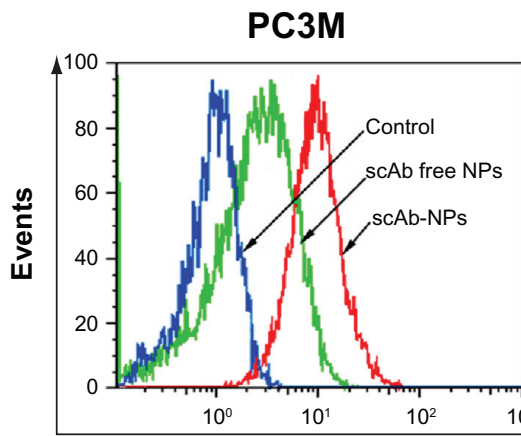

B

NP: PLGA-SPIO/DtxI

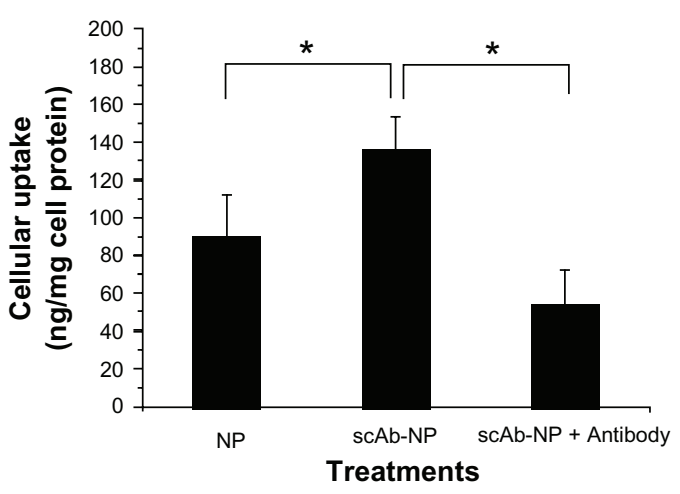

D

Fluorescence intensity

HT29

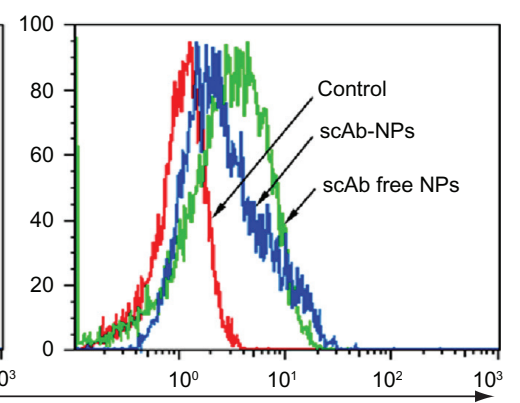

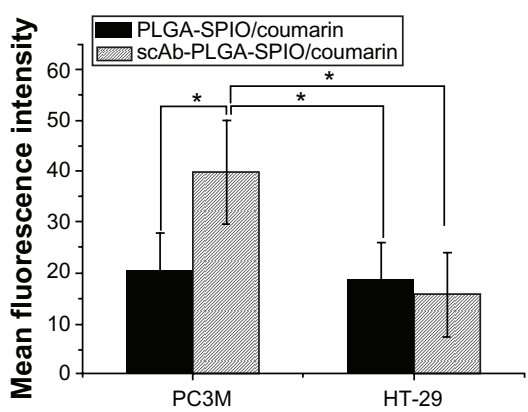

Figure 4 (A) IC $I_{50}$ of PC3M (prostate stem cell antigen-positive) cells after 24, 48, and 72 hours of incubation with docetaxel, PLGA/docetaxel, scAb-PLGA/docetaxel, PLGA-SPIO/docetaxel, or scAb-PLGA-SPIO/docetaxel. The Cell Counting Kit-8 assay was used to evaluate cytotoxicity. The data are expressed as the mean \pm standard error of the mean $(n=3)$. ${ }^{*} P$ P $<0.05$. (B) Cellular uptake in PC3M cells. PC3M cells were incubated with scAb-PLGA-SPIO/docetaxel or PLGA-SPIO/docetaxel for 2 hours, and intracellular docetaxel was measured by high-pressure liquid chromatography. To determine the competitive inhibition of uptake, excess free prostate stem cell antigen monoclonal antibodies were added to the medium prior to incubation with scAb-PLGA-SPIO/docetaxel. The results are shown as the mean \pm standard error of the mean $(n=4)$. $* P<0.05$. (C) Binding of targeted and nontargeted nanoparticles was investigated using a flow cytometer assay. PC3M and HT29 cells were incubated with void nanoparticles (control), PLGA-SPIO/coumarin (scAb-free nanoparticles), and scAb-PLGA-SPIO/coumarin (scAb nanoparticles) for 30 minutes at $37^{\circ} \mathrm{C}$, respectively. Thereafter, the cells were analyzed by flow cytometry. (D) Mean fluorescence intensity of PC $3 \mathrm{M}$ and HT29 cells in Figure $4 \mathrm{C}$. The results are shown as the mean \pm standard error of the mean $(n=3)$. $* P<0.05$.

Abbreviations: Dtxl, docetaxel; PLGA, poly(D,L-lactic-co-glycolic acid); SPIO, superparamagnetic iron oxide; NPs, nanoparticles.

increased antiproliferative effect of targeted nanoparticles in K562 leukemia cells was caused by competitive binding of nanoparticles to P-glycoprotein and resulting decrease in drug efflux. However, the exact mechanism needs to be investigated further. ${ }^{34}$ scAb-PLGA-SPIO was used as a control and showed no significant effect on inhibition of growth, indicating that docetaxel encapsulated into nanoparticles was the true source of cytotoxicity.

To investigate the possible mechanism of higher cytotoxicity of scAb-PLGA-SPIO/docetaxel than its counterpart, the level of intracellular docetaxel and a competitive binding assay were investigated. As shown in Figure 4B, scAb-PLGA-SPIO/docetaxel showed a 1.52-fold higher level of intracellular docetaxel than PLGA-SPIO/docetaxel in PC3M cells after 2 hours of incubation. However, the cellular uptake of scAb-PLGA-SPIO/docetaxel was significantly inhibited in the presence of the saturated amount of free antibodies in the medium, and the level of intracellular docetaxel was reduced to $40.6 \%$. These results suggest that the higher cytotoxicity of scAb-PLGA-SPIO/docetaxel in PC3M cells could be due to the higher intracellular level of docetaxel. Intracellular docetaxel may originate from the cellular uptake of nanoparticles and/or the release of docetaxel into the medium and subsequent cellular uptake during incubation before the wash step. Because the in vitro release profile of scAb-PLGA-SPIO/docetaxel was identical to that of PLGA-SPIO/docetaxel (Figure S3), the higher level of intracellular docetaxel is likely to be attributable to the enhanced uptake of scAb-PLGA-SPIO/docetaxel via receptor-mediated endocytosis. 


\section{In vitro nanoparticle binding and internalization assay}

The binding and internalization of targeting and nontargeting nanoparticles were investigated by flow cytometric analysis and CLSM in two cell lines with different prostate stem cell antigen expression levels. PC3M cells (prostate stem cell antigen-positive) and HT29 cells (prostate stem cell antigennegative) were used as a model with different levels of prostate stem cell antigen expression (Figure S4). As shown in Figure $4 \mathrm{C}$ and $\mathrm{D}$, a significant increase in fluorescence intensity was observed for scAb-PLGA-SPIO/coumarin compared with PLGA-SPIO/coumarin after 0.5 hours of incubation in PC3M cells (Figure 4D). In contrast, HT29 cells incubated with scAb-PLGA-SPIO/coumarin showed no significant difference in fluorescence intensity compared with PLGA-SPIO/coumarin. Meanwhile, the PC3M cells incubated with scAb-PLGA-SPIO/coumarin showed the highest fluorescence intensity, while PC3M cells incubated with PLGA-SPIO/coumarin exhibited similar fluorescence intensity relative to HT29 cells incubated with scAb-PLGASPIO/coumarin or PLGA-SPIO/coumarin. These results suggest that scAb-PLGA-SPIO/coumarin possesses potent binding affinity for prostate stem cell antigen-overexpressing PC3M cells.

Visible evidence of the targeted internalization of nanoparticles in cancer cells were obtained by CLSM. As shown in Figure 5A and B, the fluorescence intensity of scAb-PLGA-SPIO/coumarin was 2.12-fold higher than PLGA-SPIO/coumarin in PC3M cells after 2 hours of incubation. In contrast, scAb-PLGA-SPIO/coumarin showed no significantly increased accumulation in HT29 cells compared with PLGA-SPIO/coumarin. Although a little portion of coumarin could be released from the nanoparticles during the incubation period, most of the coumarin remained within the nanoparticles and was taken up into the cells as particles. Because the in vitro release profile of scAb-PLGA-SPIO/ coumarin showed a negligible difference from that of PLGASPIO/coumarin, the increased fluorescence intensity may
A

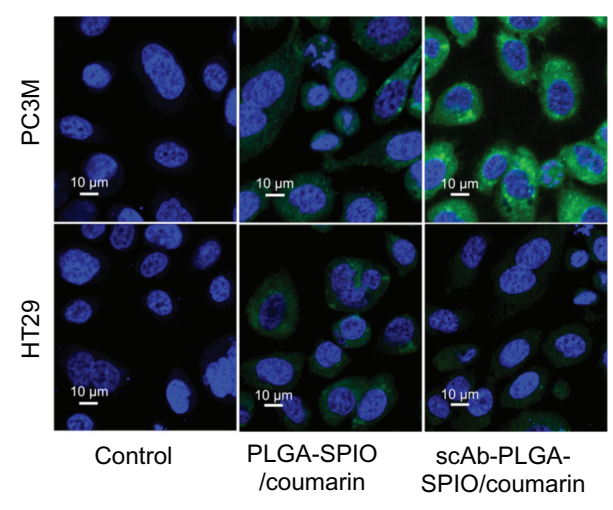

C

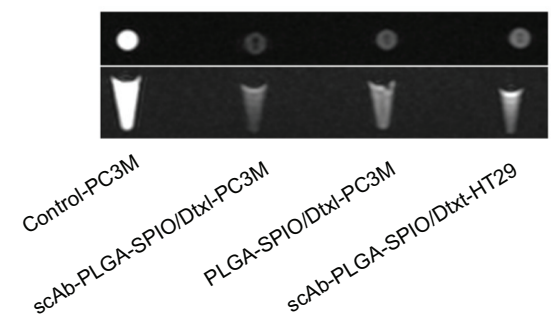

B

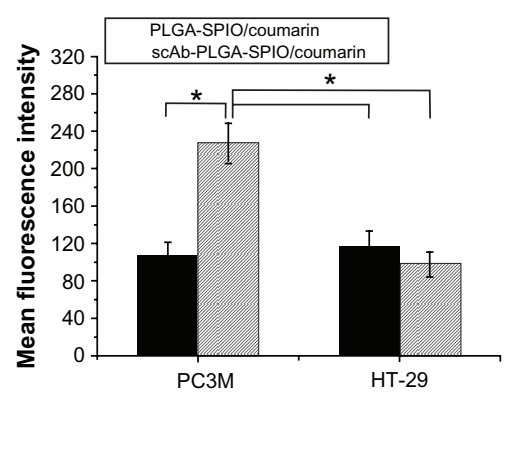

D

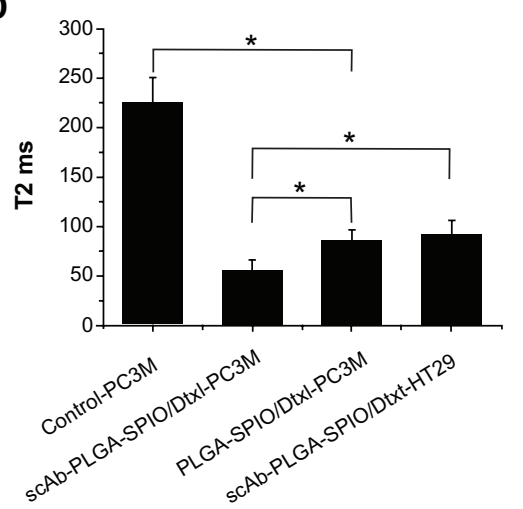

Figure 5 (A) Confocal laser scanning microscopy of PC3M cells (prostate stem cell antigen-positive) and HT29 cells (prostate stem cell antigen-negative) after 2 hours of incubation with void nanoparticles (control), PLGA-SPIO/coumarin, and scAb-PLGA-SPIO/coumarin, respectively. (B) Mean fluorescence intensity of PC3M and HT29 cells in Figure 5A. (C) In vitro T2-weighted images (cross section and sagittal section) of untreated PC3M cells, PC3M cells incubated with scAb-PLGA-SPIO/docetaxel or PLGASPIO/docetaxel, and HT29 cells incubated with scAb-PLGA-SPIO/docetaxel. (D) $\mathrm{T}_{2}$ values of PC3M and HT29 cells described in Figure 5C.

Notes: The results are shown as the mean \pm standard error of the mean $(n=3)$. $* P<0.05$.

Abbreviations: Dtxl, docetaxel; PLGA, poly(D,L-lactic-co-glycolic acid); SPIO, superparamagnetic iron oxide; NPs, nanoparticles. 
have been caused by the targeted delivery of scAb-PLGASPIO/coumarin to PC3M cells. These data are in agreement with the results obtained in the flow cytometric analysis and indicate that targeted nanoparticles are able to bind to PC3M cells effectively and become internalized by PC3M cells.

Because MRI can image at the cell level, taking advantage of excellent sensitivity and spatial resolution, ${ }^{21}$ we conducted MRI scanning to investigate the scAb-targeting specificity and cell-labeling efficiency of targeted nanoparticles. Enhancement of the effective uptake of SPION-loaded nanoparticles resulted in a significant darkening of the $\mathrm{T}_{2}$-weighted $\mathrm{MR}$ images, with loss of MR signal intensity. As shown in Figure 5C, a decrease in MRI signal intensity was observed for scAbPLGA-SPIO/docetaxel when compared with PLGA-SPIO/ docetaxel in PC3M cells, and PC3M cells incubated with scAb-PLGA-SPIO/docetaxel showed a significant negative contrast enhancement relative to HT29 cells incubated with scAb-PLGA-SPIO/docetaxel. The high-magnification images after cell uptake of scAb-PLGA-SPIO/docetaxel revealed that SPION maintained their original morphology inside the cells for a period of time. Furthermore, $\mathrm{T}_{2}$ was used to evaluate the function of MRI visibility quantitatively (Figure 5D). The untreated PC3M cells were used as a control and had a $\mathrm{T}_{2}$ of $225.3 \pm 25.3 \mathrm{msec}$, whereas all the $\mathrm{T}_{2}$ values decreased when the cells were incubated with SPION-loaded nanoparticles. PC3M cells treated with scAb-PLGA-SPIO/docetaxel had a lower $\mathrm{T}_{2}$ value in comparison with $\mathrm{PC} 3 \mathrm{M}$ cells treated with PLGA-SPIO/docetaxel or HT29 cells treated with scAb-PLGA$\mathrm{SPIO} /$ docetaxel $(55.9 \pm 10.6 \mathrm{msec}$ versus $85.4 \pm 11.2 \mathrm{msec}$ or $92.4 \pm 13.4 \mathrm{msec}, P<0.05)$. These results confirm the targeted uptake of scAb-PLGA-SPIO/docetaxel by prostate stem cell antigen-overexpressing cancer cells, but not by cancer cells that express a low level of prostate stem cell antigen.

\section{In vivo MRI}

Generally, the signal intensity of MR images is a function of the number of SPION-loaded nanoparticles in the tumor region. The efficacy of scAb-PLGA-SPIO/docetaxel in specifically targeting PC3M cells and providing MRI negative contrast enhancement in vivo was evaluated in male nude mice bearing PC3M xenografts. The $\mathrm{T}_{2}$-weighted $\mathrm{MR}$ images were acquired prior to injection and at various intervals postinjection to investigate nanoparticle accumulation to the tumor and define the optimal time window for achieving the maximal MRI contrast enhancement. MR signal intensity of tumors from untreated mice was defined at 100. As shown in Figure 6A, a negative contrast enhancement was observed in the tumors after intravenous administration, indicative of accumulation of a detectable amount of nanoparticles within the tumor, and up to maximum at 0.5 hours post-injection in both the PLGA-SPIO/docetaxel and scAb-PLGA-SPIO/ docetaxel groups. Subsequently, the normalized MR signal intensity in the tumor regions increased from $57.1 \pm 6.1$ at 0.5 hours to $94.8 \pm 3.3$ at 36 hours for PLGA-SPIO/docetaxel and from $49.1 \pm 4.5$ at 0.5 hours to $82.6 \pm 6.5$ at 36 hours for scAb-PLGA-SPIO/docetaxel (Figure 6B). Meanwhile, we did not observe a significant change in the MR signal intensity of muscle tissue. The decrease of MR contrast enhancement in the tumor with increasing time may be attributed to nanoparticle sequestration within the reticuloendothelial system. ${ }^{35}$ Moreover, after cellular internalization, hydrolytic enzymes degraded intracellular SPION, and the nanoparticles consequently lost their capacity for contrast enhancement. ${ }^{15}$ It should be noted that cancer chemotherapy would proceed with intracellular docetaxel after degradation of SPION. The MR signal intensity for scAb-PLGA-SPIO/docetaxel at 0.5 hours post-injection showed no statistical advantage
A

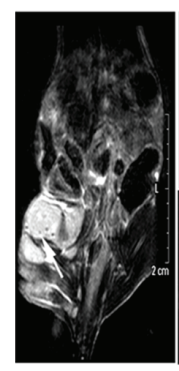

Control

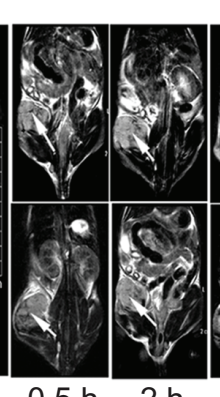

$0.5 \mathrm{~h} \quad 2 \mathrm{~h}$

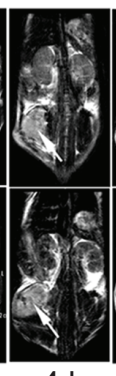

$4 \mathrm{~h}$
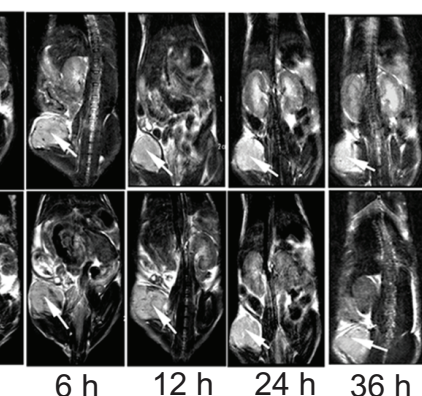

$12 \mathrm{~h} \quad 24 \mathrm{~h} \quad 36 \mathrm{~h}$
B

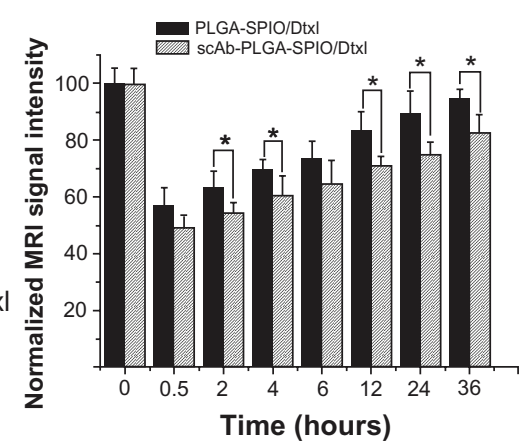

Figure 6 In vivo assessment of dual-function nanoparticles as a negative MRI contrast enhancement agent. (A) Representative MRI coronal contrast images of mice bearing PC3M xenografts prior to injection and at various intervals after systemic administration of scAb-PLGA-SPIO/docetaxel or PLGA-SPIO/docetaxel via the tail vein. The arrows indicate the location of the tumors. (B) Normalized MRI signal intensities of the PC3M xenografts in Figure 6A.

Notes: The results are shown as the mean \pm standard error of the mean $(n=3)$. $* P<0.05$.

Abbreviations: Dtxl, docetaxel; PLGA, poly(D,L-lactic-co-glycolic acid); SPIO, superparamagnetic iron oxide; MRI, magnetic resonance imaging. 
over PLGA-SPIO/docetaxel, but was lower than PLGA$\mathrm{SPIO} /$ docetaxel at 4, 6, 12, 24, and 36 hours post-injection. This may be because scAb-PLGA-SPIO/docetaxel could be taken up by $\mathrm{PC} 3 \mathrm{M}$ cells more specifically and efficiently than could PLGA-SPIO/docetaxel after accumulation in the tumor interstitium, resulting in a lower nanoparticle concentration in the tumor interstitium, more nanoparticles extravasating out of the vasculature, further facilitation of nanoparticle accumulation, and subsequently improved contrast enhancement of the tumor. However, after intravenous administration of nanoparticles, both scAb-PLGA-SPIO/ docetaxel and PLGA-SPIO/docetaxel initially accumulated in the tumor interstitium via the enhanced permeability and retention effect, which was independent of the targeting moiety, possibly leading to a lack of significant difference in MRI signal intensity at 0.5 hours post-injection.

\section{In vivo antitumor efficacy and toxicity}

To examine the therapeutic efficacy of our nanoparticles, we randomly divided mice bearing established PC3M tumors into five groups to minimize any differences in weight and tumor size between the groups after tumors had developed to about $300 \mathrm{~mm}^{3}$. As demonstrated in Figure 7A and B, no mice showed tumor regression in the phosphate-buffered
A

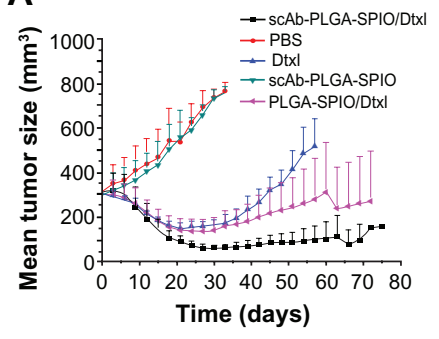

D

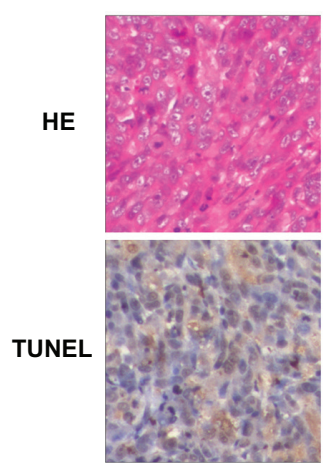

PBS

E

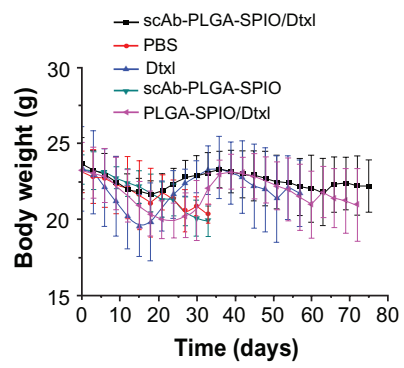

B
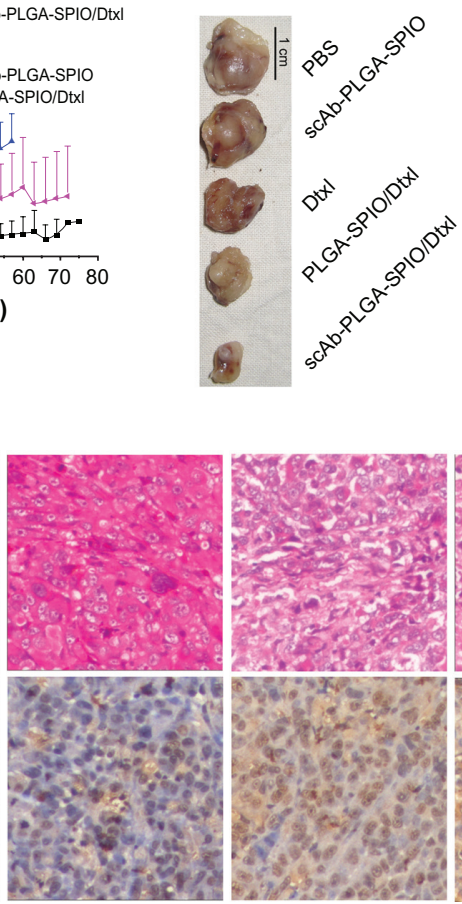

scAb-PLGA-SPIO

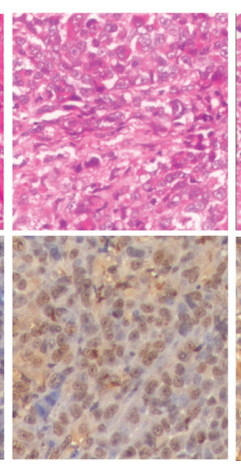

Dtxl
C
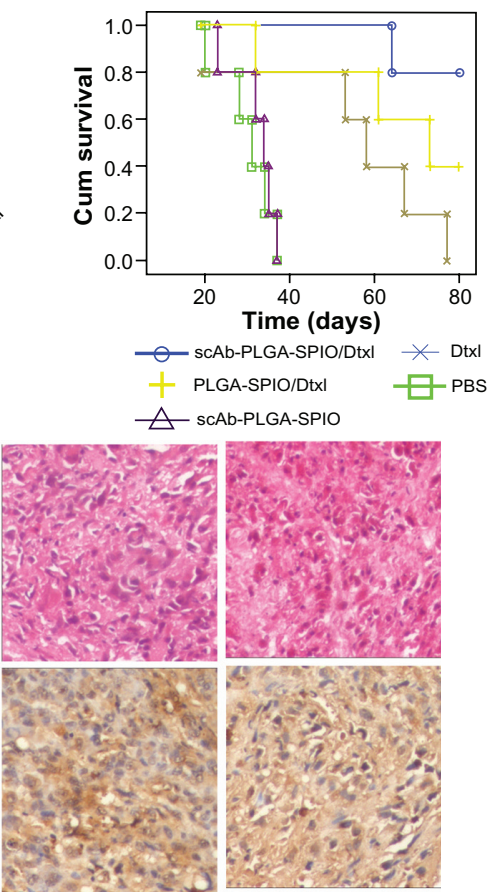

PLGA-SPIO/DtxI scAb-PLGA-SPIO/Dtx|

$\mathbf{F}$

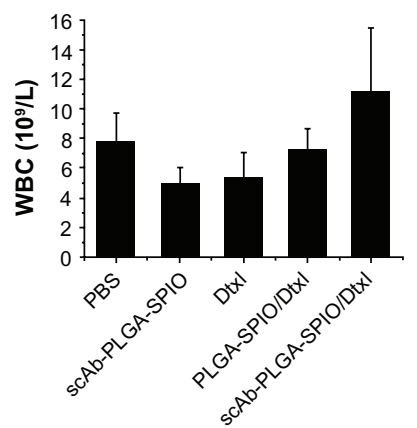

Figure 7 scAb-PLGA-SPIO/docetaxel demonstrated a superior outcome in a PC3M xenograft animal model. (A) Volumes of PC3M carcinoma in different groups. (B) Representative PC3M tumors excised from different groups. (C) Kaplan-Meier survival curve demonstrates that scAb-PLGA-SPIO/docetaxel significantly increased the lifespan of the mice. (D) Hematoxylin-eosin staining and terminal transferase uridyl nick-end labeling (TUNEL) staining of excised median tumors at I00X magnification. Histological staining was evaluated by two independent pathologists. Nuclei with dark brown horseradish peroxidase staining indicates apoptosis. (E) Body weight of the nude mice in different groups. (F) Effect of different treatments on the white blood cell counts at the endpoint of observation.

Note: The results are shown as the mean \pm standard error of the mean $(n=5)$.

Abbreviations: Dtxl, docetaxel; PLGA, poly(D,L-lactic-co-glycolic acid); SPIO, superparamagnetic iron oxide; PBS, phosphate-buffered solution. 
solution group or scAb-PLGA-SPIO group. The mice in the docetaxel group experienced initial tumor regression, but exhibited subsequent progression, and all the mice in this group reached the endpoint during the observation period (Figure 7C). In contrast, scAb-PLGA-SPIO/docetaxel and PLGA-SPIO/docetaxel induced long-term tumor inhibition, and the mean tumor volume at the endpoint of observation was $156.4 \pm 12.6 \mathrm{~mm}^{3}$ and $269.9 \pm 225.4 \mathrm{~mm}^{3}$, respectively (Figure 7A). Notably, two mice in the scAb-PLGA-SPIO/ docetaxel group experienced complete tumor regression. Furthermore, there was a significant increase in the lifespan of mice treated with scAb-PLGA-SPIO/docetaxel (Chi-square $22.514, P<0.0001)$. The numbers of animals that survived in the scAb-PLGA-SPIO/docetaxel and PLGA-SPIO/docetaxel groups were four and two at the endpoint of observation, respectively (Figure 7C). Hematoxylin-eosin staining and detection of apoptosis were performed on excised representative tumors. As shown in Figure 7D, a significant ablation of tumor mass and the presence of fibrotic tissue were observed in representative tumors from the scAb-PLGA-SPIO/ docetaxel group. A high level of apoptosis of tumor cells, as determined by TUNEL assay, was detected in tumor sections harvested from the mice treated with PLGA-SPIO/docetaxel and docetaxel, but not from the mice treated with scAbPLGA-SPIO/docetaxel. This lack of apoptosis may have been due to the presence of significant fibrotic tissue instead of tumor mass in tissue from the scAb-PLGA-SPIO/docetaxel group compared with the other groups. These results demonstrate that scAb-PLGA-SPIO/docetaxel was more efficacious in tumor inhibition than the other treatments.

In vivo toxicity was assessed by analyzing the change in white blood cells and body weight loss, which are highly susceptible to cytotoxic agents. ${ }^{14}$ In the phosphate-buffered solution and scAb-PLGA-SPIO groups, the trend for body weight loss roughly paralleled the tumor load. The mice in the docetaxel, PLGA-SPIO/docetaxel, and scAb-PLGASPIO/docetaxel groups experienced an acute decrease in body weight, and showed a maximal mean body weight loss of $15.97 \% \pm 1.91 \%, 13.96 \% \pm 3.28 \%$, and $8.28 \% \pm 5.12 \%$, respectively (Figure 7E). At the endpoint, white blood cells in all the groups were within the normal range (Figure $7 \mathrm{~F}$ ), suggesting no leukopenia or associated toxicity.

One possible explanation for the enhanced efficacy and reduced systemic toxicity of scAb-PLGA-SPIO/docetaxel compared with PLGA-SPIO/docetaxel in vivo may be that scAb-PLGA-SPIO/docetaxel was designed to bind specifically to prostate stem cell antigen on prostate cancer cells, possibly delaying nanoparticle clearance from the tumor site, increasing cellular uptake and facilitating intracellular delivery of docetaxel. Compared with scAb-PLGA-SPIO/ docetaxel, more PLGA-SPIO/docetaxel may diffuse away from the tumor site or be phagocytosed by reticuloendothelial system cells, or prematurely release docetaxel in the other organs, leading to decreased efficacy and increased toxicity. ${ }^{14}$

\section{Conclusion}

In summary, a dual-function polymer nanomedical platform was successfully developed to simultaneously provide effective prostate cancer cell-targeted MRI imaging and drug delivery, resulting in increased antitumor efficacy and MRI contrast enhancement. It is conceivable that the nanomedical platform could be easily extended to other cancers by switching the chemotherapeutic agent and targeting moiety. Thus, this targeting dual-function nanomedical platform could have potential value for drug delivery and tumor imaging in future nanomedicine.

\section{Acknowledgments}

The interdisciplinary collaboration and expert technical support of Wusheng Guo from the Department de Química of Universitat Autònoma de Barcelona is gratefully acknowledged. We also thank Minzhi Rong at the Materials Science Institute of Zhongshan University for valuable suggestions and critical reading of this manuscript. This work was supported by grants from the Chinese National Natural Science Foundation (30973011 to XG, 30901496 to JP), the 2010 Clinical Key Project of Ministry of Public Health, the Key Project of Guangdong Provincial Science and Technology Research (7117362 to XG), Medical Scientific Research Foundation of Guangdong Province of China (B2011097), Specialized Research Fund for the Doctoral Program of Higher Education of China (20110171120088), and Guangdong Science and Technology Project (2011B061200007).

\section{Disclosure}

The authors report no conflicts of interest in this work.

\section{References}

1. Tan W. Promising new treatment options for metastatic androgenindependent prostate cancer. Actas Urol Esp. 2007;31:680-685. Spanish.

2. Luo Y, Ling Y, Guo W, et al. Docetaxel loaded oleic acid-coated hydroxyapatite nanoparticles enhance the docetaxel-induced apoptosis through activation of caspase- 2 in androgen independent prostate cancer cells. J Control Release. 2010;147:278-288.

3. Medarova Z, Pham W, Kim Y, Dai G, Moore A. In vivo imaging of tumor response to therapy using a dual-modality imaging strategy. Int $J$ Cancer. 2006;118:2796-2802. 
4. Torchilin VP. Multifunctional nanocarriers. Adv Drug Deliv Rev. 2006;58:1532-1555.

5. Sengupta S, Eavarone D, Capila I, et al. Temporal targeting of tumour cells and neovasculature with a nanoscale delivery system. Nature. 2005;436:568-572.

6. Jain TK, Richey J, Strand M, Leslie-Pelecky DL, Flask CA, Labhasetwar V. Magnetic nanoparticles with dual functional properties: drug delivery and magnetic resonance imaging. Biomaterials. 2008;29:4012-4021.

7. Sanvicens N, Marco MP. Multifunctional nanoparticles - properties and prospects for their use in human medicine. Trends Biotechnol. 2008;26:425-433.

8. Yang L, Mao H, Wang YA, et al. Single chain epidermal growth factor receptor antibody conjugated nanoparticles for in vivo tumor targeting and imaging. Small. 2009;5:235-243.

9. Barat B, Sirk SJ, McCabe KE, et al. Cys-diabody quantum dot conjugates (immunoQdots) for cancer marker detection. Bioconjug Chem. 2009;20:1474-1481.

10. Serda RE, Adolphi NL, Bisoffi M, Sillerud LO. Targeting and cellular trafficking of magnetic nanoparticles for prostate cancer imaging. Mol Imaging. 2007;6:277-288.

11. Raff AB, Gray A, Kast WM. Prostate stem cell antigen: a prospective therapeutic and diagnostic target. Cancer Lett. 2009;277:126-132.

12. Reiter RE, Gu Z, Watabe T, et al. Prostate stem cell antigen: a cell surface marker overexpressed in prostate cancer. Proc Natl Acad Sci US A. 1998;95:1735-1740.

13. Schneider GF, Subr V, Ulbrich K, Decher G. Multifunctional cytotoxic stealth nanoparticles. A model approach with potential for cancer therapy. Nano Lett. 2009;9:636-642.

14. Farokhzad OC, Cheng J, Teply BA, et al. Targeted nanoparticle-aptamer bioconjugates for cancer chemotherapy in vivo. Proc Natl Acad Sci USA. 2006;103:6315-6320.

15. Thorek DL, Chen AK, Czupryna J, Tsourkas A. Superparamagnetic iron oxide nanoparticle probes for molecular imaging. Ann Biomed Eng. 2006;34:23-38.

16. Zhou J, Huang W, Wang X, et al. Prostate cancer targeted MRI nanoprobe based on superparamagnetic iron oxide and copolymer of poly (ethylene glycol) and polyethyleneimine. Chin Sci Bull. 2009;54:3137-3146.

17. Sun S, Zeng H, Robinson DB, et al. Monodisperse $\mathrm{MFe}_{2} \mathrm{O}_{4}(\mathrm{M}=\mathrm{Fe}$, Co, Mn) nanoparticles. J Am Chem Soc. 2004;126:273-279.

18. Ai H, Flask C, Weinberg B, et al. Magnetite-loaded polymeric micelles as ultrasensitive magnetic-resonance probes. Adv Mater. 2005;17: 1949-1952.

19. Wang L, Bai J, Li Y, Huang Y. Multifunctional nanoparticles displaying magnetization and near-IR absorption. Angew Chem Int Ed Engl. 2008;47:2439-2442.
20. Schneider G, Decher G. From functional core/shell nanoparticles prepared via layer-by-layer deposition to empty nanospheres. Nano Lett. 2004;4:1833-1839.

21. Chen G, Chen W, Wu Z, et al. MRI-visible polymeric vector bearing $\mathrm{CD} 3$ single chain antibody for gene delivery to $\mathrm{T}$ cells for immunosuppression. Biomaterials. 2009;30:1962-1970.

22. Kocbek P, Obermajer N, Cegnar M, Kos J, Kristl J. Targeting cancer cells using PLGA nanoparticles surface modified with monoclonal antibody. J Control Release. 2007;120:18-26.

23. Park TG, Yong LH, Sung NY. A new preparation method for protein loaded poly(D, L-lactic-co-glycolic acid) microspheres and protein release mechanism study. J Control Release. 1998;55:181-191.

24. Sahoo SK, Ma W, Labhasetwar V. Efficacy of transferrin-conjugated paclitaxel-loaded nanoparticles in a murine model of prostate cancer Int J Cancer. 2004;112:335-340.

25. Shuai X, Ai H, Nasongkla N, Kim S, Gao J. Micellar carriers based on block copolymers of poly(epsilon-caprolactone) and poly(ethylene glycol) for doxorubicin delivery. $J$ Control Release. 2004;98:415-426.

26. Wang L, Yan R, Huo Z. Fluorescence resonant energy transfer biosensor based on upconversion-luminescent nanoparticles. Angew Chem Int Ed Engl. 2005;44:6054-6057.

27. van Vlerken LE, Vyas TK, Amiji MM. Poly(ethylene glycol)-modified nanocarriers for tumor-targeted and intracellular delivery. Pharm Res. 2007;24:1405-1414.

28. Gu F, Zhang L, Teply BA, et al. Precise engineering of targeted nanoparticles by using self-assembled biointegrated block copolymers. Proc Natl Acad Sci U S A. 2008;105:2586-2591.

29. Olivier JC, Huertas R, Lee HJ, Calon F, Pardridge WM. Synthesis of pegylated immunonanoparticles. Pharm Res. 2002;19:1137-1143.

30. Zhang Z, Feng SS. In vitro investigation on poly(lactide)-tween 80 copolymer nanoparticles fabricated by dialysis method for chemotherapy. Biomacromolecules. 2006;7:1139-1146.

31. Senpan A, Caruthers SD, Rhee I, et al. Conquering the dark side: colloidal iron oxide nanoparticles. ACS Nano. 2009;3:3917-3926.

32. Links M, Brown R. Clinical relevance of the molecular mechanisms of resistance to anti-cancer drugs. Expert Rev Mol Med. 1999; 1999:1-21.

33. Minko T, Kopeckova P, Pozharov V, Kopecek J. HPMA copolymer bound adriamycin overcomes MDR 1 gene encoded resistance in a human ovarian carcinoma cell line. J Control Release. 1998;54:223-233.

34. Wang $\mathrm{X}$, Zhang $\mathrm{R}, \mathrm{Wu} \mathrm{C}$, et al. The application of $\mathrm{Fe}_{3} \mathrm{O}_{4}$ nanoparticles in cancer research: a new strategy to inhibit drug resistance. $J$ Biomed Mater Res A. 2007;80:852-860.

35. Ferrucci JT, Stark DD. Iron oxide-enhanced MR imaging of the liver and spleen: review of the first 5 years. AJR Am J Roentgenol. 1990; 155:943-950. 


\section{Supplementary materials}

\section{Overexpression of prostate stem cell antigen on the surface \\ of PC3M cells}

Western blot and immunofluorescence were used to confirm overexpression of prostate stem cell antigen as a membranebound protein. PC3M and HT29 cells were cultured in RPMI 1640 medium supplemented with $10 \%$ heat-inactivated fetal bovine serum, penicillin $100 \mathrm{U} / \mathrm{mL}$, and streptomycin $100 \mathrm{mg} / \mathrm{mL}$ under $5 \% \mathrm{CO}_{2}$ at $37^{\circ} \mathrm{C}$. For immunofluorescence, PC3M cells were seeded in a 6-well plate at a density of $2 \times 10^{5}$ cells and allowed to reach approximately $80 \%$ confluence. The PC3M cells were washed three times with phosphate-buffered solution and fixed in the presence of $4 \%$ paraformaldehyde solution for 20 minutes. The cells were blocked with goat serum for 30 minutes at room temperature and incubated overnight with mouse monoclonal prostate stem cell antigen antibody at $4^{\circ} \mathrm{C}$. After being washed with phosphate-buffered solution, the cells were incubated with FITC-labeled goat antimouse secondary antibody for one hour. The cells were washed and further incubated for another 20 minutes after addition of the DNA-staining agent, DAPI ( $1 \mathrm{mg} / \mathrm{mL})$. Images were obtained using a Zeiss Axiovert fluorescence microscope. Western blot analysis was conducted as previously described. ${ }^{1}$ Labeled bands were detected by enhanced chemiluminescence plus (ECL-plus,

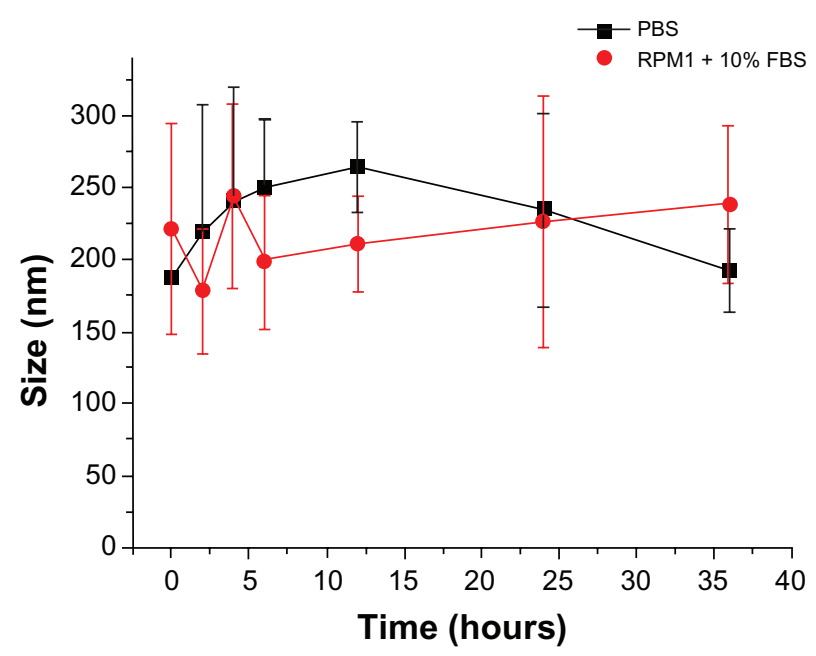

Figure SI Hydrodynamic size distribution graphs of scAb-PLGA-SPIO/docetaxel measured as a function of time upon incubation in PBS (closed squares) and RPMI containing $10 \%$ FBS.

Note: The results are shown as the mean \pm standard error of the mean $(n=3)$. Abbreviations: PBS, phosphate-buffered solution; FBS, fetal bovine serum; PLGA, poly(D,L-lactic-co-glycolic acid); SPIO, superparamagnetic iron oxide.

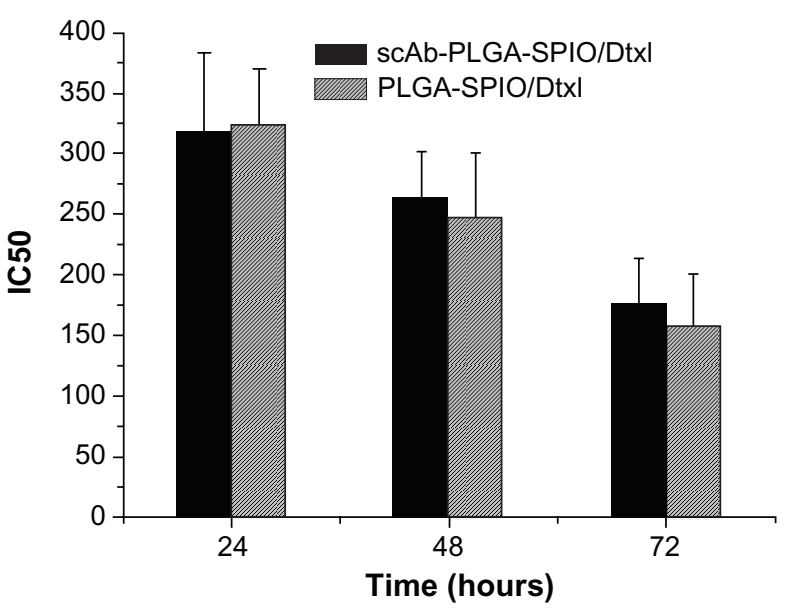

Figure S2 IC ${ }_{50}$ in HT29 (prostate stem cell antigen-negative) cells after 24, 48, or 72 hours of incubation with PLGA-SPIO/docetaxel and scAb-PLGA-SPIO/docetaxel. scAb-PLGA-SPIO/docetaxel showed no significant difference from PLGA-SPIO/ docetaxel in inhibiting the growth of HT29 cells.

Notes: The Cell Counting Kit-8 assay was used to evaluate cytotoxicity. The results are shown as the mean \pm standard error of the mean $(n=3)$.

Abbreviations: PLGA, poly(D,L-lactic-co-glycolic acid); SPIO, superparamagnetic iron oxide; Dtxl, docetaxel.

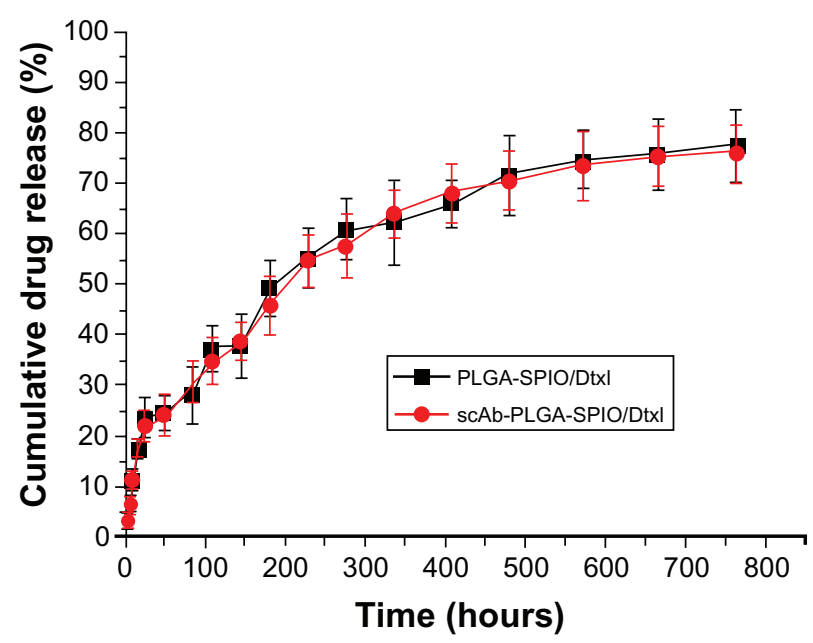

Figure S3 In vitro docetaxel release profiles of scAb-PLGA-SPIO/docetaxel and PLGA-SPIO/docetaxel. The in vitro release profile of scAb-PLGA-SPIO/docetaxel showed negligible difference from that of PLGA-SPIO/docetaxel.

Abbreviations: PLGA, poly(D,L-lactic-co-glycolic acid); SPIO, superparamagnetic iron oxide.
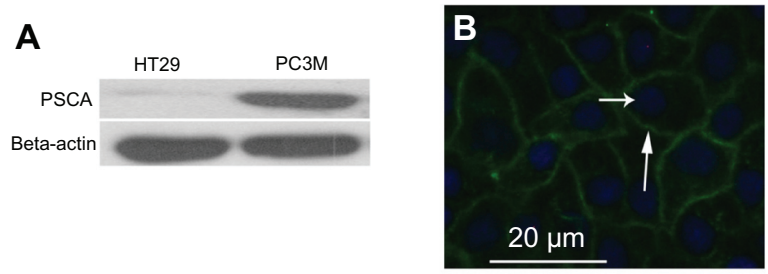

Figure S4 (A) The level of prostate stem cell antigen expression in HT29 and PC3M cells as determined by Western blot analysis. (B) Immunofluorescence images indicate that PC3M cells express prostate stem cell antigen on the cell membrane (blue, nucleus; green, prostate stem cell antigen). 
Amersham Pharmacia Biotech, Uppsala, Sweden). The bands were quantitated with the Bio-Rad VersaDoc image system (Hercules, CA). The HT29 cells were analyzed as a control.

\section{Reference}

1. Luo Y, Ling Y, Guo W, et al. Docetaxel-loaded oleic acid-coated hydroxyapatite nanoparticles enhance the docetaxel-induced apoptosis through activation of caspase- 2 in androgen independent prostate cancer cells. J Control Release. 2010;147:278-288.

\section{Publish your work in this journal}

The International Journal of Nanomedicine is an international, peerreviewed journal focusing on the application of nanotechnology in diagnostics, therapeutics, and drug delivery systems throughou the biomedical field. This journal is indexed on PubMed Central,

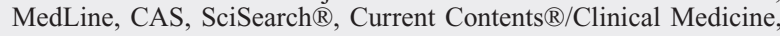

Journal Citation Reports/Science Edition, EMBase, Scopus and the Elsevier Bibliographic databases. The manuscript management system is completely online and includes a very quick and fair peer-review system, which is all easy to use. Visit http://www.dovepress.com/ testimonials.php to read real quotes from published authors.

Submit your manuscript here: http://www.dovepress.com/international-journal-of-nanomedicine-journal 